Received: 8 November 2018

Accepted: 28 December 2018

Published online: 20 February 2019

\section{Internal embryonic development in a non-copulatory, egg- laying teleost, the three-spined stickleback, Gasterosteus aculeatus}

\author{
Laura L. Dean $\mathbb{1}^{1}$, Shaun Robertson ${ }^{1}$, Muayad Mahmud ${ }^{2}$ \& Andrew D. C. MacColl ${ }^{1}$
}

The switch from egg-laying to retaining and giving birth to live young is a major transition in the history of life. Despite its repeated evolution across the fishes, records of intermediate phenotypes are vanishingly rare, with only two known cases in existence of normally egg-laying fish species retaining embryos within the ovaries. We report the discovery of a third occurrence, in which well-developed embryos were found in the ovaries of a three-spined stickleback (Gasterosteus aculeatus), a noncopulatory, normally oviparous species. Extracted from the parent fish, these embryos hatched and grew to adulthood. Genetic and physiological examination of the parent fish and offspring ruled out development by parthenogenesis and hermaphroditism, therefore implicating internal fertilisation by a male stickleback. This extremely rare phenomenon may have been facilitated in this population by an unusual tendency for females to become egg-bound, and suggests that some major transitions may arise almost spontaneously.

Major transitions, involving multifaceted and synergistic changes in multiple traits, pose an evolutionary conundrum because incomplete intermediate forms are unlikely to be functional ${ }^{1}$. Consistent with this, partially developed major transitions are extremely rare ${ }^{2,3}$, and rightly celebrated when discovered ${ }^{4-6}$. The transition from oviparity to retaining developing embryos internally and giving birth to live young involves multiple interrelated changes in physiology and behaviour and as such, has a good claim to being a major transition in the history of life $^{7-9}$. In most animal species, females reproduce oviparously, laying eggs that develop and hatch in the external environment ${ }^{7}$. In many lineages, including teleost fish, some degree of embryo retention has evolved, ranging from ovoviviparity (egg retention) to matrotrophy (placental nourishment and live birth). However, intraspecific variation in such traits is rare (but see Surget-Groba, et al. ${ }^{10}$ ), suggesting that they are under strong selection.

Despite the $>35$ independent evolutionary origins of ovoviviparity across fish lineages ${ }^{7}$, the huge number of extant egg-laying species ( $90 \%$ of bony and $43 \%$ of cartilaginous fish), and the colossal number of these that must have been examined by fish biologists, records of normally oviparous fish retaining developing embryos are incredibly rare. There are only two previous records of this phenomenon. Multiple specimens of Hemilepidotus gilberti, a marine sculpin, were discovered with eyed embryos in the ovaries of spent females, but all embryos died early in development or were deformed and would not have survived post-hatching ${ }^{11}$. A single three-spined stickleback (Gasterosteus aculeatus, Linnaeus, 1758, hereafter 'stickleback') was also found with well-developed embryos retained in the ovaries ${ }^{12}$, but embryos were not assessed for deformities or signs of life. We document a second occurrence of this phenomenon in stickleback, in which embryos, once removed from the mother, hatched and grew to adulthood without physical abnormalities.

Stickleback are a non-copulatory, oviparous, sexually reproducing species, with a simple XY sex-determining system $^{13}$. Female stickleback are batch spawners ${ }^{14}$ and can become egg-bound (with eggs overripening and hardening in the reproductive tract) if they fail to either spawn or spontaneously release their eggs ${ }^{15,16}$. Retained eggs are lost for reproduction and obstruct the release of further clutches, ultimately killing the female ${ }^{17,18}$. Despite this, egg-bound females are common in some stickleback populations ${ }^{17,19,20}$. The prolonged retention of overripe ovules is considered a non-adaptive 'accident ${ }^{\text {'16,18}}$, but ovule retention is necessary for internal fertilisation, which

${ }^{1}$ School of Life Sciences, University of Nottingham, Nottingham, NG7 2RD, UK. ${ }^{2}$ Scientific Research Center, Erbil Polytechnic University, Erbil, Iraq. Correspondence and requests for materials should be addressed to L.L.D. (email: laura.dean@nottingham.ac.uk) 
is an essential step in the transition from oviparity to live-bearing ${ }^{8}$, and thus could be considered a preadaptation to this transition. Preadaptations that arise as non-adaptive by-products of other adaptations, or initially evolve to serve a different function, may facilitate major transitions by subsequently becoming useful in a different role ${ }^{21-24}$.

We discovered an egg-bound marine stickleback in a saline coastal lagoon on North Uist, Scottish Western Isles with ovaries containing well-developed, eyed embryos. This phenomenon has at least three possible explanations, which make distinct, testable predictions: (i) the ova developed by parthenogenesis i.e. by artificial stimulation by heat, chemical or physical shock, in the absence of sperm. Parthenogenesis is common in some animal species ${ }^{25}$, and gynogenesis (development in which the embryo contains only maternal chromosomes due to activation of an egg by a sperm that degenerates without fusing with the egg nucleus) occurs in some fish ${ }^{26}$. Gynogenesis has been stimulated artificially in stickleback ${ }^{27}$, but neither gynogenesis, nor true parthenogenesis have been recorded in natural stickleback populations. This hypothesis requires the parent fish to be genetically and physiologically female and the offspring to be genetically identical to the parent. (ii) Embryos were produced hermaphroditically. Synchronous hermaphroditism, whereby mature individuals possess both functional ovaries and tests, is common in certain teleost species, although all but a single species are outcrossing ${ }^{28}$. Kryptolebias marmoratus, a mangrove killifish, is the only known hermaphroditic teleost species that predominantly self-fertilises, and is capable of releasing both fertilised and unfertilised eggs ${ }^{29,30}$. Synchronous hermaphroditism can be chemically induced in stickleback ${ }^{31}$, and an apparently hermaphroditic stickleback population exists in Alaska, from which the single other individual carrying developing embryos was collected ${ }^{12}$, making hermaphroditism an apparently strong possibility. This requires that the parent fish possesses both male and female sex organs, and the offspring carry only alleles present in the parent. (iii) Finally, eggs could have been internally fertilised by the sperm of another stickleback entering the reproductive tract from the external environment, which was the case in $H$. gilberti ${ }^{11}$. This requires the parent fish to be genetically and physiologically female, and the offspring to carry alleles from the father that were absent in the mother. We examined the gonads of the parent fish and performed genetic sex testing, alongside analysis of the allelic composition of parent and offspring to test these hypotheses. To examine the possibility that the presence of the embryos is related to a tendency by fish in the same population to retain eggs, we compared the prevalence of egg-bound gravid females across stickleback populations on North Uist.

\section{Results}

Analysis of gonads. The parent fish possessed ovaries containing two clutches of eggs, the older (proximal to the cloaca) of which contained many developing embryos (Fig. 1A,B). Embryos were distributed throughout the older clutch and had reached stage 21 of 24 stages of embryonic development in stickleback ${ }^{32}$, Fig. 1C,D. Embryo viability was confirmed by the observation of a heartbeat, and no physical abnormalities, or deformities were observed. Three independent researchers agreed that the gonads of the parent fish contained no testicular tissue (Supplementary Fig. S1), and none was evident elsewhere in the body cavity. Once raised to adulthood, offspring were crossed successfully in vitro.

Sex determination and microsatellites. Microsatellite analysis revealed that the offspring were not genetically identical to the parent fish, or to one another (Table 1). The parent fish was homozygous at four of six microsatellite loci, while two of the offspring were heterozygous at five of six loci (Table 1). Of the 56 offspring, 19 possessed at least one allele that was not present in the parent.

The parent fish was determined to be genetically female by all three sex determining loci (Table 1 ), while both sexes were present in the offspring (Table 1$)$, but there were more females (42/56 offspring) than males (14/56 offspring, $\left.X^{2}=14, d f=1, p<0.001\right)$.

Prevalence of egg retention across populations. There was a strong correlation between body length and number of eggs in the ovaries of normally gravid females $(\mathrm{r}=0.91, \mathrm{t}=32.24, d f=226, p<0.0001$, Fig. 2). Egg-bound females, which were found only in Faik, the origin of the parent fish, had almost twice the number of eggs in their ovaries than normally gravid females of a similar size (Fig. 2). Of the 10 gravid marine females in Faik, two were egg-bound (20\%), while none of the 208 gravid females from 23 other populations on North Uist were egg-bound $\left(\chi^{2}=24.22, d f=1, p<0.0001\right.$, Fig. 2$)$.

\section{Discussion}

We identified a clutch of almost fully developed embryos inside the ovaries of a stickleback; a non-copulatory, oviparous species. Embryos had developed normally inside the fish, to the stage of eyeing and body pigmentation, one of the final stages of embryonic development in stickleback ${ }^{32}$, likely corresponding to approximately 5-6 days post-fertilisation, with no visible signs of deformity. This is contrary to the one other known case of internal fertilisation in a non-copulatory fish, where embryos found in the ovaries bore significant deformities ${ }^{11}$. The embryos we removed from the parent fish were viable and fertile, since they hatched, grew to adulthood and were successfully crossed in vitro in the lab. However, it is not possible to know whether they would have survived to hatching inside the parent fish, nor whether they would have been able to exit the ovaries, or survive in the wild without the male parental care that is normal in stickleback ${ }^{33}$.

The parent fish was physiologically and genetically female, therefore the embryos cannot have been produced hermaphroditically. Hermaphroditism was implicated as the most likely explanation for the single other record of internally developed embryos in stickleback ${ }^{12}$, however, close inspection of diagrammatic representations of the internal anatomy of stickleback in Greenbank and Nelson ${ }^{12}$, figures 11 and 12, reveals that the authors misinterpreted the normal reproductive anatomy of stickleback as hermaphroditism. We also showed that the offspring we collected were a mix of genetically male and female individuals, and carried alleles for three microsatellite markers that were absent in the mother. This rules out parthenogenesis, and, therefore, the eggs must have been 

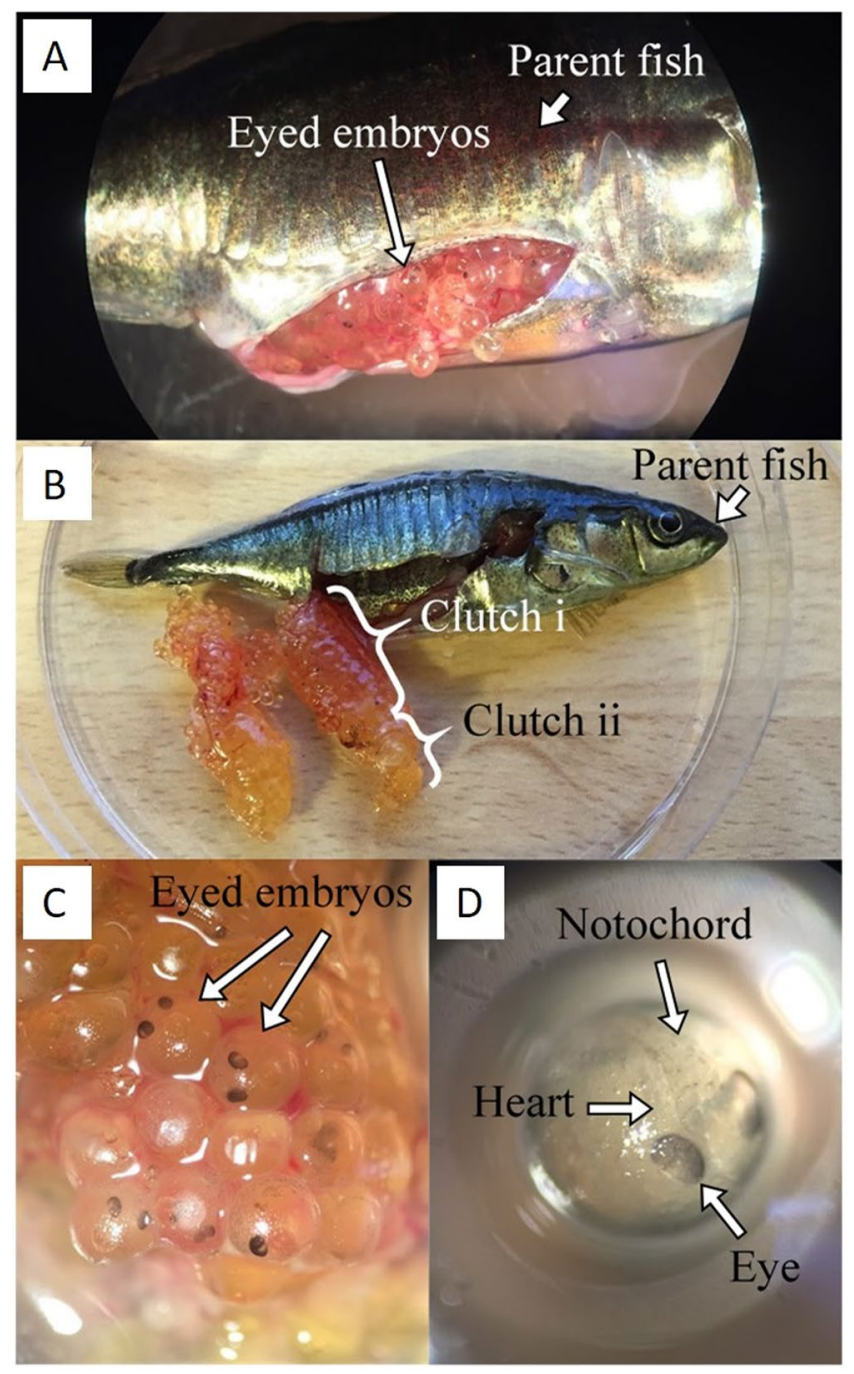

Figure 1. Images of internally developing embryos. (A) A female stickleback with ovaries containing internally developing embryos. (B) Two developing clutches of eggs in the ovaries. (C) A cluster of embryos removed from the ovary, and (D) a single embryo removed from the ovary showing developed eyespots, notochord and heart. Photographs were taken by LD.

\begin{tabular}{|c|c|c|c|c|c|c|c|}
\hline \multirow[b]{2}{*}{ Marker } & \multirow[b]{2}{*}{$\begin{array}{l}\text { Sex } \\
\text { determining }\end{array}$} & \multicolumn{3}{|c|}{ Parent fish } & \multicolumn{3}{|c|}{ Offspring } \\
\hline & & \begin{tabular}{|l|} 
Homo \\
$(1,1)$
\end{tabular} & \begin{tabular}{|l|} 
Hetero \\
$(1,2)$
\end{tabular} & \begin{tabular}{|l|} 
Homo \\
$(2,2)$
\end{tabular} & $\begin{array}{l}\text { Homo } \\
(1,1)\end{array}$ & \begin{tabular}{|l|} 
Hetero \\
$(1,2)$
\end{tabular} & \begin{tabular}{|l} 
Homo \\
$(2,2)$
\end{tabular} \\
\hline$I d h$ & $\mathrm{Y}$ & 0 & 0 & 1 & 0 & 15 & 41 \\
\hline Gasm6 & $\mathrm{Y}$ & 0 & 0 & 1 & 0 & 14 & 42 \\
\hline Stn190 & $\mathrm{Y}$ & 1 & 0 & 0 & 0 & 13 & 43 \\
\hline Stn57 & $\mathrm{N}$ & 0 & 1 & 0 & 5 & 5 & 4 \\
\hline Stn201 & $\mathrm{N}$ & 0 & 1 & 0 & 6 & 5 & 3 \\
\hline Stn317 & $\mathrm{N}$ & 1 & 0 & 0 & 14 & 0 & 0 \\
\hline
\end{tabular}

Table 1. Genotypes of parent fish and offspring. For sex determining loci, heterozygosity designates males. Homo: homozygous, Hetero: heterozygous.

fertilised internally by a separate, male individual. Furthermore, developing embryos were distributed throughout the older clutch of eggs, some well away from the cloaca, indicating that sperm were able to penetrate almost the entirety of the ovaries. The ovarian fluid of female stickleback greatly prolongs sperm motility to facilitate spawning in freshwater ${ }^{34,35}$, and females may prefer to spawn with males whose nests already contain the eggs of other females $^{36}$, thus, we hypothesise that sperm most likely entered the reproductive tract of the parent fish via contact with recently fertilised eggs in a nest. 


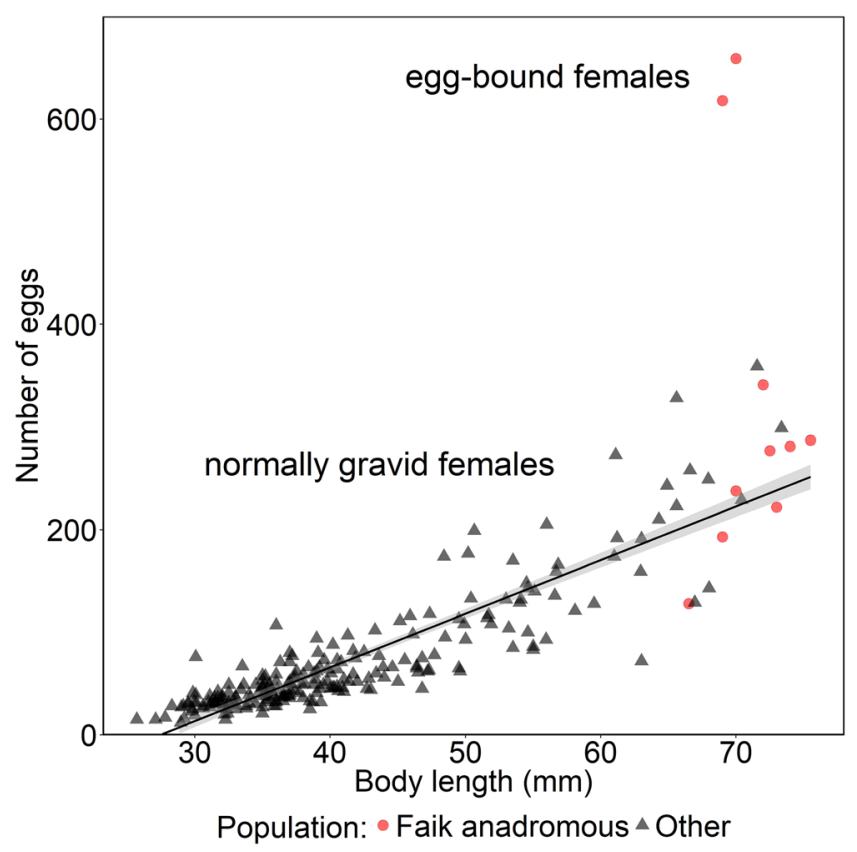

Figure 2. Relationship between body length and number of eggs in normally gravid females. Graph shows the correlation back transformed from the log-log relationship. Red circles: gravid Faik marine females, black triangles: gravid females from 23 other North Uist populations, grey ribbon: \pm S.E for normally gravid females.

The fact that the embryos had reached such an advanced stage of development indicates that the ovaries of female stickleback provide a suitable environment for embryonic development. Stickleback embryos acquire all the necessary energy for growth from the yolk provided by the mother within the egg ${ }^{37}$, and although they would not normally develop internally, are capable of modulating their exposure to maternally derived, potentially harmful chemicals ${ }^{38}$. This could explain why embryonic development was not adversely affected by the chemical/hormonal environment of the mother. However, a rich oxygen supply is necessary for proper embryonic development and male stickleback invest heavily in parental care of the eggs, including frequent fanning to increase oxygen delivery ${ }^{39,40}$. Ovoviviparous fish specifically regulate the dissolved oxygen content in ovarian fluid according to embryonic requirements ${ }^{41}$, but whether this is possible in stickleback is not known. Nonetheless, the normal development of embryos inside the ovaries in this case indicates that there must have been sufficient oxygen for normal development, and that both female stickleback and their embryos already possess many of the preadaptations necessary for embryos to develop within the ovaries.

Given the extensive research that has been conducted on stickleback, a model organism ${ }^{42-44}$, and oviparous fish in general, the fact that internal embryonic development has only been recorded once before in stickleback ${ }^{12}$, and only once more across all other normally oviparous fish ${ }^{11}$, suggests that it is extremely uncommon. The population to which the parent fish belonged had an increased tendency towards prolonged egg retention $(20 \%$ of anadromous females in Faik were egg-bound, while no egg-bound females were found across 23 other populations), which could increase the likelihood of accidental internal fertilisation during failed egg-laying attempts. However, egg-bound females have been observed in other stickleback populations ${ }^{14,17}$, and oviparous fish spe$\operatorname{cies}^{18,45-47}$, with no record of internal embryonic development. Nonetheless, prolonged egg retention could be a preadaptation that facilitates the transition to internal embryonic development. We cannot know whether such isolated incidence of the internal retention of developing embryos indicates the nascent evolution of a transition to live-bearing, but they do suggest that such transitions are possible and can arise more or less spontaneously.

\section{Methods}

Fish collection, dissection and egg husbandry. As part of an ongoing program to breed stickleback and collect data on life history, gravid females have been sampled over several years (2007-2018) from many lochs and coastal lagoons on the Scottish Hebridean island of North Uist using un-baited minnow traps (Gee traps, Dynamic Aqua, Vancouver) set overnight. A single brackish lagoon, Fairy Knoll (“Faik", 57 $38^{\prime} 7^{\prime} \mathrm{N} ; 7^{\circ} 12^{\prime} 54^{\prime} \mathrm{W}$ ), appeared to have a consistently high abundance of egg-bound females with $\sim 1-3$ being found each year. When suspected egg-bound females were caught, they were euthanized and dissected as below and always found to be egg-bound with unfertilised over-ripe ovules. As a result of the prevalence of egg-bound females, breeding females in Faik were monitored in an ad-hoc way for a number of years and on $24^{\text {th }}$ April 2015 a gravid female marine stickleback, displaying the classic 'berried' abdomen of an egg-bound fish ${ }^{17}$, was caught in this lagoon. The fish was transported to the laboratory in aerated loch water and euthanized on arrival by overdose of MS222 anaesthesia, followed by destruction of the brain, in accordance with Schedule One of UK Home Office regulations. Following dissection, eggs containing developing embryos were identified inside the intact peritoneal membranes surrounding the ovaries. Eggs, and all internal organs were thoroughly examined, particularly for the 
presence of testicular tissue, using a light microscope. Eggs containing developing embryos were kept in chilled $1 \%$ saline solution and transported to aquaria at the University of Nottingham. Between four and seven days following the dissection, 56 fry hatched and were raised to adulthood in the lab. Adult offspring were subsequently crossed in vitro to determine fertility. Following the discovery of the stickleback containing fertilised embryos, further sampling efforts were made in Faik between April and May of 2015, 2016 and 2017 to find more females in the same condition, but only females egg-bound with over-ripe ovules were found. All methods were carried out in accordance with the Animals (Scientific Procedures) Act 1986 and all experimental protocols were approved by the University of Nottingham Animal Welfare and Ethical Review Body (AWERB), and conducted by licenced personnel under the UK Home Office Project Licence 30/3415.

Sex determination and microsatellite analysis. The gonads of the parent fish were fixed, stained, sectioned (see Supplementary Material for detailed methodology), and examined thoroughly for the presence of testicular tissue by three independent researchers to determine physiological sex. Genetic sex determination was conducted on the parent fish and 56 offspring by PCR amplification (see Supplementary Table S1 for PCR primers) of three loci: Idh, Gasm6 and Stn190, which, combined, produce an accurate determination of sex ${ }^{48}$. To further assess whether a second individual contributed to the genetic make-up of the offspring three additional sets of microsatellite loci (Stn57, Stn201 and Stn317) were also analysed for the parent fish and 14 randomly selected offspring.

DNA was collected by running a single sterile swab over both flanks of each fish and extracted using a proteinase K extraction procedure. Swab heads containing DNA samples were removed and placed on ice in individual Eppendorf tubes prior to DNA extraction. DNA was extracted using Viagen DirectPCR Lysis Reagent (Mouse Tail), following the manufacturers standard protocol with the following modifications. $270 \mu \mathrm{l}$ of DirectPCR Lysis Reagent and $30 \mu \mathrm{l}$ proteinase $\mathrm{K}$ were added to each swab and samples were incubated for 5 hours at $55^{\circ} \mathrm{C}$ whilst rotating at $250 \mathrm{rpm}$. The swab head was removed from each tube, and the solution then incubated at $85^{\circ} \mathrm{C}$ for 45 minutes before cooling to room temperature. All PCR reactions were carried out in $20 \mu$ volumes containing $6 \mu \mathrm{l}$ nuclease-free $\mathrm{H}_{2} 0,10 \mu \mathrm{L} 2 \mathrm{X}$ Biomix red reaction mix (Bioline), $1 \mu \mathrm{l}$ of both forward and reverse primers $(10 \mu \mathrm{M})$ and $2 \mu \mathrm{l}$ of template DNA (approximately $20 \mathrm{ng}$ ). For all PCRs, thermocycling was set up as follows: Initial denaturation at $96^{\circ} \mathrm{C}$ for two minutes, followed by 35 cycles of denaturation at $96^{\circ} \mathrm{C}$ for 30 seconds, annealing at $56^{\circ} \mathrm{C}$ for 30 seconds and extension at $70^{\circ} \mathrm{C}$ for 30 seconds, followed by a final extension at $70^{\circ} \mathrm{C}$ for two minutes. To score genotypes, PCR products were electrophoresed on a $4 \%$ agarose gel run at $100 \mathrm{~V}$ for one hour, alongside a $100 \mathrm{bp}$ DNA ladder. For sex testing primers the presence of a single band indicated a female and the presence of a double band indicated a male. On the few occasions where the result of one primer pair differed from the others, the sex of the fish was assumed to be that of which two out of the three pairs of primers agreed. For all six microsatellite loci the occurrence of alleles in the offspring that are not present in the mother indicated that a second individual contributed to the genetic make-up of the offspring.

Analysis of egg-bound females. During April-May of 2007-2008 and 2010-2011, 230 gravid female stickleback were collected from 24 populations on North Uist (Supplementary Table S2). Females were euthanized as above, measured for standard length and dissected. Ovaries were removed and all eggs were counted and assessed for signs of being overripe ${ }^{17}$.

Statistical analysis. Statistical analyses were carried out in R version 3.4.4 $4^{49}$. To test for a correlation between body length and number of eggs in normally gravid females (egg-bound females were excluded because of their substantial increase in number of eggs), both variables were log transformed and a t-test based on Pearson's correlation was used. To test whether the sex ratio in the offspring differed from an expected ratio of 50:50, and to test for differences in the prevalence of egg-bound females in the marine population in Faik, compared with all other populations sampled on North Uist combined (Supplementary Table S2), chi-squared tests were used.

\section{Data Availability}

Egg count and microsatellite data are provided as supplementary material.

\section{References}

1. Mivart, S. G. J. On the genesis of species. (D. Appleton \& Company, 1871).

2. Koonin, E. V. The Biological Big Bang model for the major transitions in evolution. Biology Direct 2, https://doi.org/10.1186/17456150-2-21 (2007)

3. Maynard Smith, J. \& Szathmary, E. The major transitions in evolution. (Oxford University Press, 1995).

4. Friedman, M. The evolutionary origin of flatfish asymmetry. Nature 454, 209-212, https://doi.org/10.1038/nature07108 (2008).

5. Demere, T. A., McGowen, M. R., Berta, A. \& Gatesy, J. Morphological and molecular evidence for a stepwise evolutionary transition from teeth to baleen in mysticete whales. Systematic Biology 57, 15-37, https://doi.org/10.1080/10635150701884632 (2008).

6. Suzuki, T. K., Tomita, S. \& Sezutsu, H. Gradual and contingent evolutionary emergence of leaf mimicry in butterfly wing patterns. Bmc Evolutionary Biology 14, https://doi.org/10.1186/s12862-014-0229-5 (2014).

7. Blackburn, D. In Encyclopedia of reproduction Vol. 4 (eds Ernst. Knobil \& Jimmy. D. Neill) 994-1103 (Academic Press, 1999).

8. Wourms, J. P. \& Lombardi, J. Reflections on the evolution of piscine viviparity. American Zoologist 32, 276-293 (1992).

9. Goodwin, N. B., Dulvy, N. K. \& Reynolds, J. D. Life-history correlates of the evolution of live bearing in fishes. Philosophical Transactions of the Royal Society B-Biological Sciences 357, 259-267, https://doi.org/10.1098/rstb.2001.0958 (2002).

10. Surget-Groba, Y. et al. Multiple origins of viviparity, or reversal from viviparity to oviparity? The European common lizard (Zootoca vivipara, Lacertidae) and the evolution of parity. Biological Journal of the Linnean Society 87, 1-11, https://doi.org/10.1111/j.10958312.2006.00552.x (2006).

11. Hayakawa, Y. \& Munehara, H. Facultatively internal fertilization and anomalous embryonic development of a non-copulatory sculpin Hemilepidotus gilberti Jordan and Starks (Scorpaeniformes: Cottidae). Journal of Experimental Marine Biology and Ecology 256, 51-58, https://doi.org/10.1016/s0022-0981(00)00303-8 (2001). 
12. Greenbank, J. \& Nelson, P. R. In Fishery Bulletin 153 from Fishery Bulletin of the Fish and Wildlife Service Vol. 59 (United States Government Printing Office, 1959).

13. Peichel, C. L. et al. The master sex-determination locus in threespine sticklebacks is on a nascent $\mathrm{Y}$ chromosome. Current Biology 14, 1416-1424, https://doi.org/10.1016/j.cub.2004.08.030 (2004).

14. Roufidou, C. et al. Hormonal changes over the spawning cycle in the female three-spined stickleback. Gasterosteus aculeatus. General and comparative endocrinology 257, 97-105, https://doi.org/10.1016/j.ygcen.2017.07.030 (2018).

15. Springate, J. R. C., Bromage, N. R., Elliott, J. A. K. \& Hudson, D. L. The timing of ovulation and stripping and their effects on the rates of fertilization and survival to eyeing, hatch and swim-up in the Rainbow trout (Salmo gairdneri R). Aquaculture 43, 313-322, https://doi.org/10.1016/0044-8486(84)90032-2 (1984).

16. Bromage, N. et al. Broodstock management, fecundity, egg quality and the timing of egg-production in the rainbow trout (Oncorhynchus mykiss). Aquaculture 100, 141-166, https://doi.org/10.1016/0044-8486(92)90355-o (1992).

17. Lam, T. J., Nagahama, Y., Chan, K. \& Hoar, W. S. Overripe eggs and postovulatory corpora lutea in the threespine stickleback, Gasterosteus aculeatus L., form trachurus. Canadian Journal of Zoology 59, 2029-2036, https://doi.org/10.1139/z78-273 (1978).

18. Hansen, O. J., Puvanendran, V. \& Bangera, R. Broodstock diet with water and astaxanthin improve condition and egg output of brood fish and larval survival in Atlantic cod, Gadus morhua L. Aquaculture Research 47, 819-829, https://doi.org/10.1111/are.12540 (2016).

19. Roufidou, C. et al. Overripening of eggs and changes in reproductive hormones in the threespine stickleback. Gasterosteus aculeatus. Evolutionary Ecology Research 17, 583-601 (2016).

20. Borg, B. \& Vanveen, T. Seasonal effects of photoperiod and temperature on the ovary of the three-spined stickleback, Gasterosteus aculeatus L. Canadian Journal of Zoology-Revue Canadienne De Zoologie 60, 3387-3393, https://doi.org/10.1139/z82-428 (1982).

21. Gould, S. J. Is a new and general theory of evolution emerging? Paleobiology 6, 119-130 (1980).

22. Bock, W. J. Preadaptation and multiple evolutionary pathways. Evolution 13, 194-211, https://doi.org/10.1111/j.1558-5646.1959. tb03005.x (1959).

23. Bock, W. J. \& Vonwahlert, G. Adaptation and the form - function complex. Evolution 19, 269-299, https://doi.org/10.2307/2406439 (1965).

24. Prum, R. O. \& Brush, A. H. The evolutionary origin and diversification of feathers. Q. Rev. Biol. 77, 261-295, https://doi. org/10.1086/341993 (2002).

25. Simon, J. C., Delmotte, F., Rispe, C. \& Crease, T. Phylogenetic relationships between parthenogens and their sexual relatives: the possible routes to parthenogenesis in animals. Biological Journal of the Linnean Society 79, 151-163, https://doi.org/10.1046/j. 1095-8312.2003.00175.x (2003).

26. Beukeboom, L. W. \& Vrijenhoek, R. C. Evolutionary genetics and ecology of sperm-dependent parthenogenesis. Journal of Evolutionary Biology 11, 755-782, https://doi.org/10.1007/s000360050117 (1998).

27. Samonte-Padilla, I. E., Eizaguirre, C., Scharsack, J. P., Lenz, T. L. \& Milinski, M. Induction of diploid gynogenesis in an evolutionary model organism, the three-spined stickleback (Gasterosteus aculeatus). Bmc Developmental Biology 11, 55-66, https://doi. org/10.1186/1471-213x-11-55 (2011).

28. Avise, J. C. \& Mank, J. E. Evolutionary Perspectives on Hermaphroditism in Fishes. Sexual Development 3, 152-163, https://doi. org/10.1159/000223079 (2009).

29. Avise, J. C. \& Tatarenkov, A. Population genetics and evolution of the mangrove rivulus Kryptolebias marmoratus, the world's only self-fertilizing hermaphroditic vertebrate. Journal of Fish Biology 87, 519-538, https://doi.org/10.1111/jfb.12741 (2015).

30. Tatarenkov, A. et al. Genetic Subdivision and Variation in Selfing Rates Among Central American Populations of the Mangrove Rivulus, Kryptolebias marmoratus. Journal of Heredity 106, 276-284, https://doi.org/10.1093/jhered/esv013 (2015).

31. Bernhardt, R. R., von Hippel, F. A. \& Cresko, W. A. Perchlorate induces hermaphroditism in threespine sticklebacks. Environmental Toxicology and Chemistry 25, 2087-2096, https://doi.org/10.1897/05-454r.1 (2006).

32. Swarup, H. Stages in the development of the stickleback Gasterosteus aculeatus (L). Journal of Embryology and Experimental Morphology 6, 373-383 (1958).

33. Stein, L. R. \& Bell, A. M. Consistent individual differences in fathering in threespined stickleback Gasterosteus aculeatus. Current Zoology 58, 45-52, https://doi.org/10.1093/czoolo/58.1.45 (2012).

34. Elofsson, H., Van Look, K. J. W., Sundell, K., Sundh, H. \& Borg, B. Stickleback sperm saved by salt in ovarian fluid. Journal of Experimental Biology 209, 4230-4237, https://doi.org/10.1242/jeb.02481 (2006).

35. Elofsson, H., McAllister, B. G., Kime, D. E., Mayer, I. \& Borg, B. Long lasting stickleback sperm; is ovarian fluid a key to success in fresh water? Journal of Fish Biology 63, 240-253, https://doi.org/10.1046/j.1095-8649.2003.00153.x (2003).

36. Ridley, M. \& Rechten, C. Female stickleback prefer to spawn with males whose nests contain eggs. Behaviour 76, 152-161, https:// doi.org/10.1163/156853981x00059 (1981).

37. Wootton, R. J. In The evolutionary biology of the threespine stickleback (eds Bell, M. A. \& Foster, S. A.) (Oxford University Press, 1994).

38. Paitz, R. T., Bukhari, S. A. \& Bell, A. M. Stickleback embryos use ATP-binding cassette transporters as a buffer against exposure to maternally derived cortisol. Proceedings of the Royal Society B-Biological Sciences 283, 20152838, https://doi.org/10.1098/ rspb.2015.2838 (2016).

39. Reebs, S. G., Whoriskey, F. G. \& Fitzgerald, G. J. Diel patterns of fanning activity, egg respiration, and the nocturnal behavior of male three-spined sticklebacks, Gasterosteus aculeatus L (f. trachurus). Canadian Journal of Zoology-Revue Canadienne De Zoologie 62, 329-334, https://doi.org/10.1139/z84-051 (1984).

40. Sargent, R. C. \& Gebler, J. B. Effects of nest site concealment in hatching success, reproductive success, and paternal behavior of the threespine stickleback. Gasterosteus aculeatus. Behavioral Ecology and Sociobiology 7, 137-142, https://doi.org/10.1007/bf00299519 (1980).

41. Boehlert, G. W., Kusakari, M. \& Yamada, J. Oxygen consumption of gestating female Sebastes schlegeli - estimating the reproductive cost of livebearing. Environmental Biology of Fishes 30, 81-89, https://doi.org/10.1007/bf02296879 (1991).

42. McKinnon, J. S. \& Rundle, H. D. Speciation in nature: the threespine stickleback model systems. Trends in Ecology \& Evolution 17, 480-488, https://doi.org/10.1016/s0169-5347(02)02579-x (2002).

43. Peichel, C. L. \& Marques, D. A. The genetic and molecular architecture of phenotypic diversity in sticklebacks. Philosophical transactions of the Royal Society of London. Series B, Biological sciences 372, 20150486 (2017).

44. Hendry, A. P., Bolnick, D. I., Berner, D. \& Peichel, C. L. Along the speciation continuum in sticklebacks. Journal of Fish Biology 75, 2000-2036, https://doi.org/10.1111/j.1095-8649.2009.02419.x (2009).

45. Treasurer, J. W. \& Holliday, F. G. T. Some aspects of the reproductive biology of Perch Perca fluviatilis L. A histological description of the reproductive cycle. Journal of Fish Biology 18, 359-376, https://doi.org/10.1111/j.1095-8649.1981.tb03778.x (1981).

46. Speare, E. P. Fecundity and egg survival of the central johnny darter (Etheostoma nigrum nigrum) in Southern Michagan. Copeia 3, 308-314 (1965)

47. Feindel, N. J., Benfey, T. J. \& Trippel, E. A. Gonadal development of triploid Atlantic Cod Gadus morhua. Journal of Fish Biology 78, 1900-1912, https://doi.org/10.1111/j.1095-8649.2011.02955.x (2011).

48. Toli, E. A., Calboli, F. C. F., Shikano, T. \& Merila, J. A universal and reliable assay for molecular sex identification of three-spined sticklebacks (Gasterosteus aculeatus). Molecular Ecology Resources 16, 1389-1400, https://doi.org/10.1111/1755-0998.12543 (2016).

49. R: a language and environment for statistical computing v. Version 3.4.1 (R Foundation for Statistical Computing, Vienna, Austria, 2017). 


\section{Acknowledgements}

We are grateful to Ann Lowe, Alan Crampton and Anthony Ducker for fish husbandry and all members of the MacColl lab for useful discussions. This work was supported by the Natural Environment Research Council [grant numbers NE/L002604/1, NE/J02239X/1], the first grant is a NERC DTP studentship to L.L.D. and the second grant to A.D.C.M.

\section{Author Contributions}

L.L.D. wrote the manuscript, conducted lab work and data analysis. S.R. and M.M. conducted lab work. A.D.C.M. performed the fish dissection, collected data on female egg number and helped draft the manuscript.

\section{Additional Information}

Supplementary information accompanies this paper at https://doi.org/10.1038/s41598-019-38584-w.

Competing Interests: The authors declare no competing interests.

Publisher's note: Springer Nature remains neutral with regard to jurisdictional claims in published maps and institutional affiliations.

(c) (i) Open Access This article is licensed under a Creative Commons Attribution 4.0 International License, which permits use, sharing, adaptation, distribution and reproduction in any medium or format, as long as you give appropriate credit to the original author(s) and the source, provide a link to the Creative Commons license, and indicate if changes were made. The images or other third party material in this article are included in the article's Creative Commons license, unless indicated otherwise in a credit line to the material. If material is not included in the article's Creative Commons license and your intended use is not permitted by statutory regulation or exceeds the permitted use, you will need to obtain permission directly from the copyright holder. To view a copy of this license, visit http://creativecommons.org/licenses/by/4.0/.

(C) The Author(s) 2019 